\title{
Preface - How to select a journal?
}

\author{
T. Czigány*
}

Department of Polymer Engineering, Faculty of Mechanical Engineering, Budapest University of Technology and Economics, Müegyetem rkp. 3., H-1111 Budapest, Hungary

\section{Dear Readers,}

You read the first issue of the ninth volume of eXPRESS Polymer Letters. We express our thanks to our authors, referees and readers for the increasing trust towards our journal reflected by the number of regular readers, downloads and by the continuous improvement of our impact factor. The latest impact factor of XXPRESS Polymer Letters is 2.953, meaning almost $30 \%$ improvements over that in the previous year. One year before we decided to become the member of the 'elite club', i.e. the group of the top $25 \%$ journals. This goal was reached as we are within the first $17 \%$ of the journals having impact factors. One can ask, of course whether the impact factor is the only thing distinguishing the journals from each other? After all, how should one select the proper journal for a manuscript nowadays when we are overloaded day by day by offers from newly launched journals? The first important rule is to be acquainted with the relevant literature, which already gives a hint where similar articles are published. This is important as it may happen that a very good article is submitted to a 'wrong' journal. In such cases there are usually two scenarios: The first is that the article is published in the given journal, however the interested readers will not find it, and as a result the article will not be cited, which is disadvantageous both for the journal and the author. Another possibility is that the editor refuses to publish the paper with and without reasoning. This may be annoying for the author, but in the long term, it serves his/her interest. The second most important rule is that based on the knowledge of the current literature the authors should be able to assess the quality of the paper, which may help in deciding whether to submit it to a journal

\footnotetext{
${ }^{*}$ Corresponding author, e-mail: czigany@eik.bme.hu (C) BME-PT
}

with impact factor, or to a local, or newly established journal. This latter category should be treated with reservation, as 'bluff' journals are proliferating, where papers are published without reviewing and edition, although publication costs are charged. The third most important rule of manuscript submission is again based on the knowledge of the literature: a proper order should be established for the journals thematically appropriate for the manuscript, which is typically based on their impact factors. The higher the impact factor of the journal the higher the probability that more colleagues will read them, thus one can be sure that the article will reach the interested readers. It is not by chance that a common part of all three rules is the proper knowledge of the literature, as without this it is impossible to write a good article or to select the proper journal. If one is convinced about the originality and novelty of the manuscript, one should dare to submit it to the best journals, as e.g. eXPRESS Polymer Letters.

I wish a proper journal selection for all authors, readers and referees of $\boldsymbol{e X P R E S S}$ Polymer Letters and I wish to announce the March issue that will be dedicated to professor Karger-Kocsis, the chief editor of eXPRESS Polymer Letters on the occasion of his $65^{\text {th }}$ birthday. Sincerely yours,

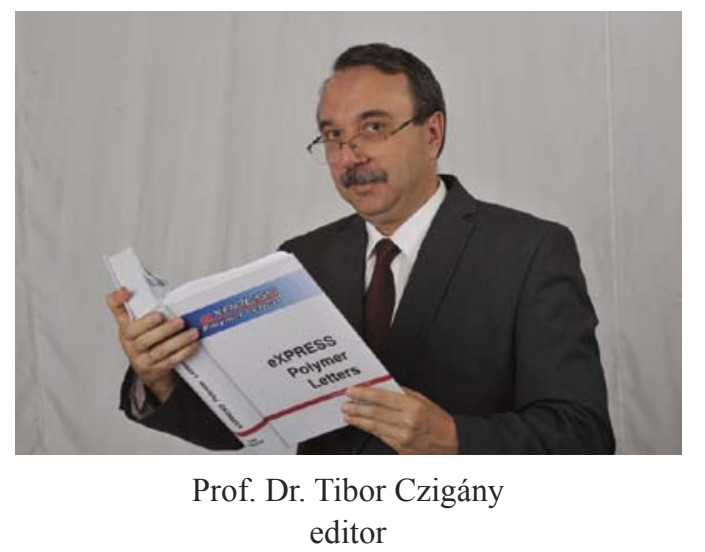

